\title{
FAKTOR PENYEBAB MEDICATION ERROR DI INSTALASI GAWAT DARURAT (IGD) RUMAH SAKIT BHAYANGKARA TK.III MANADO
}

\author{
Leydia G. Angkow ${ }^{1)}$, Gayatri Citraningtyas ${ }^{1)}$, Weny I. Wiyono ${ }^{1)}$ \\ ${ }^{1)}$ Program Studi Farmasi FMIPA UNSRAT Manado, 95115
}

\begin{abstract}
Patients who enter the ECU room need fast and appropriate help, but in reality there are reports of Medication Errors in the ECU. The purpose of this research is to find out the causes factors of Medication Error in the prescribing and dispensing phase. This research is a descriptive study with prospective data collection using questionnaires. The results showed that the factors causing Medication Error on prescribing phase error included the workloads that were unbalanced of workloads and human resources $(H R)$, interruptions which were interrupted by ringing the telephone, communication such as the incomplete writing of drug names, environmental conditions such as the temperature working area was less supportive while working, and education, namely prescription writing that does not meet the prescription completeness requirements. Factors that causes Medication Error on dispensing phase include workloads of health workers are not able to solve on the every of their own job, interruptions that interrupting working by telephone ringing, environmental conditions on the work area temperature is less supportive when working, education such as preparation of drugs that are not in recipe request, and communication, namely the communication system regarding the stock of pharmaceutical supplies in the Pharmacy Installation did not run smoothly.
\end{abstract}

Keywords: Causes, Medication Error, Emergency Room, Bhayangkara Hospital.

\begin{abstract}
ABSTRAK
Pasien yang masuk IGD perlu pertolongan yang cepat dan tepat, namun kenyataannya terdapat pelaporan kejadian Medication Error di IGD. Tujuan penelitian yaitu mengetahui faktor penyebab Medication Error pada fase prescribing dan dispensing. Penelitian ini merupakan penelitian deskriptif dengan pengambilan data secara prospektif menggunakan kuisioner. Hasil penelitian menunjukkan bahwa faktor penyebab Medication Error fase prescribing meliputi beban kerja yaitu beban kerja dan SDM tidak seimbang, gangguan/interupsi bekerja yaitu terganggu dengan dering telepon, komunikasi yaitu penulisan nama obat tidak lengkap, kondisi lingkungan yaitu suhu area kerja kurang mendukung saat bekerja, dan edukasi yaitu penulisan resep yang tidak memenuhi syarat kelengkapan resep. Faktor penyebab Medication Error fase dispensing meliputi beban kerja yaitu tenaga kesehatan tidak mampu menyelesaikan sendiri setiap pekerjaan, gangguan/interupsi bekerja yaitu terganggu dengan dering telepon, kondisi lingkungan yaitu suhu area kerja kurang mendukung saat bekerja, edukasi yaitu penyiapan obat yang tidak sesuai permintaan resep dan komunikasi yaitu sistem komunikasi mengenai stok perbekalan farmasi di Instalasi Farmasi tidak berjalan lancar.
\end{abstract}

Kata Kunci: Faktor penyebab, Medication Error, Instalasi Gawat Darurat, Rumah Sakit Bhayangkara 


\section{PENDAHULUAN}

Kesalahan pengobatan (Medication Error) didefinisikan sebagai kegagalan/ kurangnya keberhasilan dalam proses pengobatan yang mengarah atau memiliki potensi yang dapat menyebabkan kerugian pada pasien (Aronson, 2009). Angka kejadian Medication Error di Indonesia belum terdata secara akurat dan sistematis, tetapi angka kejadian Medication Error sangat sering dijumpai di berbagai institusi pelayanan kesehatan di Indonesia. Berdasarkan studi yang dilakukan Patanwala (2010) menyatakan sebanyak 178 kesalaan pengobatan terjadi dari 194 pasien di Instalasi Gawat Darurat (IGD), kesalahan terbanyak terjadi pada fase prescribing 53,90\% dan fase administrasi 34,80\%.

Kunjungan pasien IGD Rumah Sakit Bhayangkara per hari sekitar 50-60 pasien sedangkan jumlah tempat tidur hanya 10. Jumlah tenaga kesehatan di IGD sebanyak 27 orang yang terdiri dari 11 dokter dan 16 perawat, dengan pembagian shift yaitu pagi 7 orang ( 2 dokter, 3 perawat, 1 kepala ruangan, 1 admin), siang ( 2 dokter dan 3 perawat) dan malam (2 dokter dan 3 perawat). Menurut Permenkes Nomor 56 (2014), jumlah kebutuhan tenaga perawat dihitung dengan perbandingan 2 (dua) perawat untuk 3 (tiga) tempat tidur. Melihat dari jumlah perawat per shift rasio antara beban kerja dan Sumber Daya Manusia (SDM) tidak seimbang.

IGD Rumah Sakit Bhayangkara tidak memiliki depo farmasi sendiri sehingga resep pasien IGD ditebus di Instalasi Farmasi Rumah Sakit. Resep yang masuk di Instalasi farmasi Rumah Sakit Bhayangkara setiap hari rata-rata 200 lembar resep yaitu seluruh resep yang masuk baik resep rawat jalan (poliklinik), instalasi gawat darurat dan rawat inap. Jumlah tenaga kesehatan Instalasi Farmasi Rumah Sakit Bhayangkara terdiri dari 2 apoteker, 5 asisten apoteker, 2 perawat dan 1 tenaga kesehatan lainnya dengan jam kerja yaitu 24 jam per shift hanya 2 orang. Melihat kondisi tersebut adanya beban kerja dari tenaga kesehatan, sehingga ada kemungkinan terjadinya kesalahan pengobatn (Medication Error). Menurut Ojerinde (2014) kesalahaan pengobatan dapat disebabkan oleh faktor situasional berupa faktor fisiologis seperti kelelahan akibat stres kerja, pekerjaan yang belebihan, kurang tidur, dan faktor psikologis.

Menurut Menteri Kesehatan RI (2004) kesalahan pengobatan (Medication Error) sebetulnya dapat dicegah. Karena itu perlu untuk mengetahui faktor penyebabnya agar dapat mencegah terjadinya Medication Error. Berdasarkan latar belakang di atas maka peneliti tertarik melakukan pengkajian mengenai faktor penyebab Medication Error dalam pelayanan kefarmasian di Instalasi Gawat Darurat (IGD) Rumah Sakit Bhayangkara Tk.III Manado.

\section{METODOLOGI PENELITIAN}

Penelitian ini dilakukan di IGD dan Instalasi Farmasi Rumah Sakit Bhayangkara Manado pada bulan Oktober 2018 - Mei 2019. Jenis penelitian deskriptif dengan pengambilan data secara prospektif. Populasi dalam penelitian ini yaitu seluruh tenaga kesehatan yang terlibat dalam proses prescribing dan dispensing yaitu Dokter, Apoteker, Asisten Apoteker, dan Perawat di IGD dan Instalasi Farmasi Rumah Sakit Bhayangkara Manado. Sampel penelitian ini diambil dengan menggunakan metode total sampling yaitu seluruh populasi dalam penelitian dijadikan sebagai subjek penelitian. Pengumpulan data dawali dengan peyebaran kuisioner. Kuisioner tersebut di adaptasi dari kuisioner Donsu (2016) yang terdiri dari data penelitian karakteristik 
responden dan kuesioner tentang faktor penyebab Medication Error yang diberikan kepada responden yang terlibat dalam proses prescribing dan dispensing resep pasien IGD. Kuesioner yang telah selesai diisi oleh responden dikumpulkan kembali untuk selanjutnya diolah.

Analisis data yang digunakan dalam penelitian ini adalah analisis univariat dimana data akan ditampilkan atau disajikan dalam bentuk tabel frekuensi dan persentase. Data di analisa dengan menetapkan kriteria penilaian. Penilaian menggunakan skala Likert dengan cara menetapkan bobot jawaban terhadap tiap item yaitu skor pernyataan positif dengan pilihan: Sangat Setuju (SS) bernilai 4, Setuju (S) bernilai 3, Kurang Setuju (KS) bernilai 2 dan Tidak Setuju (TS) bernilai 1.

Tiap item pernyataan dijumlahkan bobot jawaban dan dihitung persentasenya sehingga didapatkan total skor pada masingmasing pernyataan. Skor terendah untuk tiap pernyataan pada masing-masing faktor penyebab dipilih dan selanjutnya dideskripsikan sebagai faktor-faktor penyebab ME fase prescribing dan dispensing pada pelayanan kefarmasian di IGD Rumah Sakit Bhayangkara Manado.

\section{HASIL DAN PEMBAHASAN}

Faktor Penyebab Medication Error pada Fase Prescrbing

Tabel 1. Karakteristik Responden

\begin{tabular}{lccc}
\hline NO & Karakteristik & $\begin{array}{c}\text { Frekue } \\
\text { nsi }\end{array}$ & $\begin{array}{c}\text { Persentas } \\
\text { e (\%) }\end{array}$ \\
\hline 1. & Umur & & \\
& $20-30$ tahun & 17 & 81 \\
& $31-40$ tahun & 2 & 9 \\
$41-50$ tahun & 0 & 0 \\
$51-60$ tahun & 1 & 5 \\
& > 60 tahun & 1 & 5 \\
\hline Total & 21 & 100 \\
\hline
\end{tabular}

\begin{tabular}{|c|c|c|c|}
\hline \multirow[t]{3}{*}{2.} & \multicolumn{3}{|l|}{ Jenis Kelamin } \\
\hline & Perempuan & 17 & 81 \\
\hline & Laki-laki & 4 & 19 \\
\hline & Total & 21 & 100 \\
\hline \multirow[t]{7}{*}{3.} & Pendidikan & & \\
\hline & D3/Sederajat & 4 & 19 \\
\hline & $\mathrm{S} 1$ & 12 & 57 \\
\hline & S1 Profesi & 3 & 14 \\
\hline & $\mathrm{S} 2$ & 0 & 0 \\
\hline & Lainnya & 2 & 10 \\
\hline & Total & 21 & 100 \\
\hline \multirow[t]{10}{*}{4.} & Pekerjaan & & \\
\hline & Dokter Umum & 10 & 48 \\
\hline & Dokter & & \\
\hline & Spesialis & 1 & 5 \\
\hline & Apoteker & 2 & 9.5 \\
\hline & Asisten & & \\
\hline & Apoteker & 5 & 23 \\
\hline & Perawat & 2 & 9.5 \\
\hline & Lainnya & 1 & 5 \\
\hline & Total & 21 & 100 \\
\hline \multirow[t]{6}{*}{5.} & Lama Kerja & & \\
\hline & $<1$ tahun & 8 & 38.1 \\
\hline & $1-5$ tahun & 7 & 33.3 \\
\hline & $6-10$ tahun & 3 & 14.3 \\
\hline & $>10$ tahun & 3 & 14.3 \\
\hline & Total & 21 & 100 \\
\hline \multicolumn{4}{|c|}{$\begin{array}{l}\text { Berdasarkan hasil yang didapat, } \\
\text { mayoritas umur responden adalah } 20-30 \\
\text { tahun sebanyak } 17 \text { responden }(81 \%) \text {, dengan } \\
\text { mayoritas jenis kelamin responden adalah } \\
\text { perempuan sebanyak } 17 \text { responden ( } 81 \%) \text {, } \\
\text { dengan mayoritas pendidikan S1 sebanyak } \\
12 \text { responden (57\%), dengan mayoritas } \\
\text { pekerjaan dokter umum sebanyak } 10 \\
\text { responden (48\%) dan lama bekerja terbanyak } \\
<1 \text { tahun sebanyak } 8 \text { responden }(38.1 \%) \text {. }\end{array}$} \\
\hline \multicolumn{4}{|c|}{ Tabel 2. Faktor Penyebab Prescibing Error } \\
\hline $\begin{array}{l}\text { Faktor } \\
\text { Penyebab }\end{array}$ & $\begin{array}{l}\text { or } \\
\text { ebab }\end{array}$ & & $\mathbf{N} \%$ \\
\hline Komunikasi & $\begin{array}{ll}\text { inikasi } & \begin{array}{l}\text { Penulis } \\
\text { obat ler }\end{array}\end{array}$ & & \\
\hline
\end{tabular}




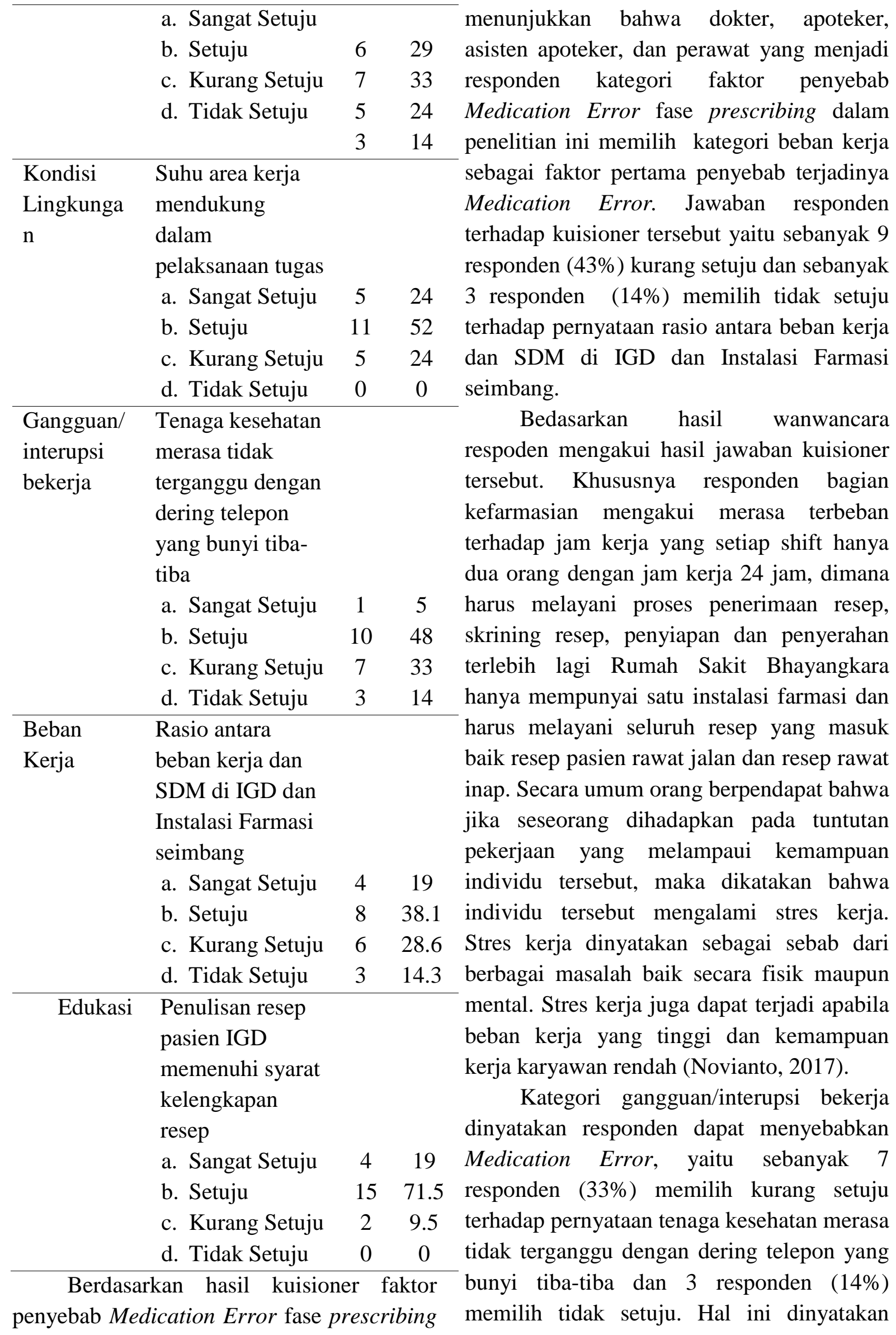


responden lewat wawancara bahwa dering telepon yang bunyi tiba-tiba dapat mempengaruhi kosentrasi baik sebagai dokter saat menuliskan resep dan tenaga farmasi saat menyiapkan obat. Menurut Notoatmodjo (2003), dering telepon dapat menganggu konsentrasi kerja yang dapat menyebabkan pekerja cenderung berbuat kesalahan dan akhirnya menurunkan produktivitas bekerja.

Komunikasi termasuk dalam faktor penyebab Medication Error pada fase prescribing, sebanyak 5 responden (24\%) menyatakan kurang setuju dan sebanyak 3 responden (14\%) tidak setuju terhadap pernyataan penulisan nama obat lengkap. Hal ini diakui lewat wawancara dimana ada beberapa nama obat pada resep tidak ditulis lengkap contohnya paracetamol di singkat PCT, vitamin b-compleks hanya ditulis bc, cetrizine ditulis CTZ dan lainya. Resep adalah permintaan tertulis dari seorang dokter yang diberi izin berdasarkan peraturan perundang-undangan yang berlaku kepada apoteker untuk menyiapkan dan atau membuat, meracik serta menyerahkan obat kepada pasien (Syamsuni,2006). Karena adanya hubungan antara dokter dengan tenaga farmasi dalam fase prescribing ini sehingga komunikasi yang baik perlu adanya, dan berdasarkan wawancara tenaga farmasi selalu mengkonfirmasikan kembali kepada dokter terhadap resep yang tidak jelas sebelum diberikan kepada pasien, sehingga pemberian obat yang rasional, tepat, aman, efektif dan ekonomis.

Kondisi lingkungan termasuk dalam kategori faktor penyebab Medication Error, hal ini ditunjukan lewat hasil kuisioner bahwa sebanyak 11 responden (24\%) memilih kurang setuju suhu area kerja mendukung dalam pelaksanaan tugas tenaga kesehatan. Ruangan IGD RS Bhayangkara memiliki empat $\mathrm{AC}$, namun berdasarkan wawacara dengan tenaga kesehatan AC tersebut sudah tidak berfungsi dengan baik sehingga ketika banyaknya jumlah pasien pada siang hari menyebabkan suhu ruangan IGD menjadi gerah, hal tersebut menjadi salah satu faktor penyebab stres yang dapat mengganggu kosentrasi dalam melaksanakan tugas. Donsu (2016) menyatakan, gangguan lingkungan yang tidak nyaman seperti berisik, gerah, pencahayaan yang terlalu terang atau redup, suasana kerja yang tidak harmonis, gangguan telepon, desain ruangan yang tidak memenuhi syarat, kelebihan beban kerja karena SDM kurang, dsb merupakan sumber stress bagi para petugas.

Berdasarkan hasil skor, edukasi masuk dalam kategori faktor terakhir penyebab Medication Error pada fase prescribing, yaitu sebanyak 2 responden (9.5\%) kurang setuju penulisan resep memenuhi syarat kelengkapan resep. Masalah kelengkapan resep yang sering terjadi adalah penulisan nama obat tidak lengkap dan tidak jelas, namun ketika terjadi ketidaklengkapan resep tenaga farmasi langsung menghubungi dokter penulis resep untuk mengkonfirmasi obat sebelum diberikan kepada pasien. Menurut Bayang (2013), ketika resep yang bermasalah tersebut akan dikonfirmasi kepada penulisnya dapat menghambat proses pengobatan pasien.

\section{Faktor Penyebab Medication Error pada Fase Dispensing}

Tabel 3. Karakteristik Responden

\begin{tabular}{llcc}
\hline NO & Karakteristik & $\begin{array}{c}\text { Frek } \\
\text { uensi }\end{array}$ & $\begin{array}{c}\text { Persentase } \\
(\%)\end{array}$ \\
\hline 1. & Umur & & \\
& $20-30$ tahun & 20 & 77 \\
& $31-40$ tahun & 4 & 15 \\
& $41-50$ tahun & 0 & 0
\end{tabular}


PHARMACON- PROGRAM STUDI FARMASI, FMIPA, UNIVERSITAS SAM RATULANGI,

Volume 8 Nomor 2 Mei 2019

\begin{tabular}{lcc}
$51-60$ tahun & 1 & 4 \\
$>60$ tahun & 1 & 4 \\
\hline Total & 26 & 100
\end{tabular}

2. Jenis Kelamin

\begin{tabular}{lcc} 
Perempuan & 18 & 69 \\
Laki-laki & 8 & 31 \\
\hline Total & 26 & 100 \\
\hline
\end{tabular}

\section{Pendidikan}

D3/Sederajat $\quad 10 \quad 42$

S1 833

S1 Profesi $\quad 6 \quad 25$

\begin{tabular}{lcc} 
S2 & 0 & 0 \\
\hline Total & 24 & 100
\end{tabular}

4. Pekerjaan

Apoteker

$2 \quad 8$

Asisten

Apoteker

5

Perawat

18

19

Lainnya

69

\begin{tabular}{lcc} 
Lainnya & 1 & 4 \\
\hline Total & 26 & 100
\end{tabular}

\section{Lama Kerja}

$<1$ tahun

$1-5$ tahun

$6-10$ tahun

17

4

$6-10$ tahun

3

65

\begin{tabular}{ccc}
$>10$ tahun & 5 & 19 \\
\hline Total & 26 & 100 \\
\hline
\end{tabular}

Berdasarkan tabel 3, dapat diketahui bahwa mayoritas umur responden adalah 20 - 30 tahun sebanyak 20 responden (77\%), mayoritas jenis kelamin responden adalah perempuan sebanyak 18 responden (69\%), mayoritas pendidikan D3/Sederajat sebanyak 10 responden (42\%), dengan mayoritas pekerjaan perawat sebanyak 18 responden (69\%) dan lama bekerja terbanyak 1-5 tahun sebanyak 17 responden (65\%).

Tabel 4. Faktor Penyebab Dispensing Error

\begin{tabular}{|c|c|c|c|}
\hline $\begin{array}{c}\text { Faktor } \\
\text { Penyebab }\end{array}$ & Pernyataan & $\mathbf{N}$ & $\%$ \\
\hline Komunikasi & Sistem & & \\
\hline
\end{tabular}

komunikasi

mengenai stok

perbekalan

farmasi di

instalasi farmasi

berjalan lancar

$\begin{array}{lcc}\text { a. Sangat Setuju } & 9 & 35 \\ \text { b. Setuju } & 12 & 46 \\ \text { c. Kurang Setuju } & 5 & 19 \\ \text { d. Tidak Setuju } & 0 & 0\end{array}$

Kondisi

Suhu area kerja

Lingkungan

mendukung

dalam

pelaksanaan tugas

tenaga kesehatan

$\begin{array}{lcc}\text { a. Sangat Setuju } & 7 & 27 \\ \text { b. Setuju } & 13 & 50 \\ \text { c. Kurang Setuju } & 6 & 23 \\ \text { d. Tidak Setuju } & 0 & 0\end{array}$

Gangguan/

Tenaga kesehatan

interupsi

bekerja

merasa tidak

terganggu dengan

dering telepon

yang bunyi tiba-

tiba

$\begin{array}{lcc}\text { a. Sangat Setuju } & 4 & 15 \\ \text { b. Setuju } & 11 & 42 \\ \text { c. Kurang Setuju } & 9 & 35 \\ \text { d. Tidak Setuju } & 2 & 8\end{array}$

Beban kerja

Tenaga kesehatan

mampu

menyelesaikan

sendiri setiap

pekerjaan

$\begin{array}{lcc}\text { a. Sangat Setuju } & 4 & 15 \\ \text { b. Setuju } & 9 & 35 \\ \text { c. Kurang Setuju } & 10 & 38.5 \\ \text { d. Tidak Setuju } & 3 & 11.5\end{array}$

Edukasi

Penyiapan obat

untuk pasien IGD

sesuai dengan

permintaan pada

resep

a. Sangat Setuju $6 \quad 23$ 


$\begin{array}{lcc}\text { b. Setuju } & 16 & 62 \\ \text { c. Kurang Setuju } & 4 & 15 \\ \text { d. Tidak Setuju } & 0 & 0\end{array}$

Berdasarkan hasil kuisioner faktor penyebab Medication Error fase dispensing menunjukkan bahwa apoteker, asisten apoteker, dan perawat yang menjadi responden dalam peneitian ini mempersepsikan beban kerja sebagai kategori faktor pertama yang dapat menyebabkan Medication Error pada fase dispesing. Dispensing adalah proses penyiapan dan penyerahan obat kepada orang yang namanya tertulis pada resep (Siregar, 2006). Dalam proses penyiapan obat tenaga kefarmasian melakukan skrining resep, menginput obat, menulis etiket, menyalin instruksi pemberian obat ke KPO (Kartu Pencatatan Obat), penyiapan obat untuk satu hari pemakaian, pengemasan obat, pengecekan kembali, penyerahan obat kepada pasien serta serah terima dengan perawat yang selanjutnya dilakukan pengecekan kembali oleh perawat sebelum diserahkan kepada pasien. Hasil jawaban kuisioner terhadap beban kerja yaitu sebanyak 10 responden $(38.5 \%)$ memilih kurang setuju dan 3 responden (11.5\%) tidak setuju tenaga kesehatan mampu menyelesaikan sendiri setiap pekerjaan. Berdasarkan hasil wawancara tenaga kefarmasian dan perawat mengakui sangat berpengaruhnya jumlah pasien berlebih dengan kurangnya petugas pada setiap jam kerja. Dalam penelitian Donsu (2016) menyatakan proses dispensing akan dipengaruhi oleh tingginya beban kerja atau kurangnya staf, adanya interupsi dan distraksi.

Berdasarkan hasil skor pada proses dispensing responden mempersepsikan gangguan/interupsi bekerja sebagai faktor kedua penyebab terjadinya Medication Error dengan kategori pernyataan yang sama seperti pada fase prescribing yaitu tenaga kesehatan merasa tidak terganggu dengan dering telepon yang bunyi tiba-tiba yaitu sebanyak 9 responden (35\%) kurang setuju dan sebanyak 2 responden (8\%) tidak setuju terhadap pernyataan tersebut. Ruangan IGD dan Instalasi Farmasi memiliki tempat dan tata ruang yang tanpa sekat, terbuka, minim privasi sehingga menyebabkan suara percakapan, suara dering telepon dapat mengganggu produktivitas pegawai. Karena suara-suara yang tidak dapat diramalkan seperti suara dering telepon, suara percakapan atau peralatan kantor dapat memberikan pengaruh negatif dan menganggu konsentrasi pegawai (Robbins, 2002).

Kondisi lingkungan juga menjadi faktor penyebab Medication Error pada proses dispensing, sebanyak 6 responden (23\%) kurang setuju terhadap pernyataan suhu area kerja mendukung dalam pelaksanaan tugas tenaga kesehatan. Peningkatan suhu dapat menghasilkan kenaikan prestasi kerja, namun disisi lain dapat pula menurunkan prestasi kerja. Kenaikan suhu pada batas tertentu dapat menimbulkan semangat yang akan merangsang prestasi kerja, tetapi setelah melewati ambang batas tertentu kenaikan suhu ini sudah mulai mengganggu suhu tubuh yang dapat mengakibatkan terganggunya prestasi kerja. Menurut Fitriyaningsih (2008), suasana lingkungan kerja yang menyenangkan akan dapat mempengaruhi karyawan dalam pekerjaannya. Bekerja dalam lingkungan kerja yang menyenangkan merupakan harapan sekaligus impian dari setiap pekerja. Sehingga setiap organisasi atau perusahaan harus mengusahakan agar lingkungan kerja 
dimana pegawai berada selalu dalam kondisi yang baik.

Tenaga Kesehatan pada proses dispensing mempersepsikan edukasi dan komunikasi termasuk dalam faktor penyebab Medication Error. 4 responden (15\%) menyatakan kurang setuju penyiapan obat untuk pasien IGD sesuai dengan permintaan pada resep dan sebanyak 2 responden (19\%) menyatakan kurang setuju sistem komunikasi mengenai stok perbekalan farmasi di intalasi farmasi berjalan lancar. Berdasarkan hasil wawancara ketidaklancaran ini dikarenakan kurangnya stok perbekalan farmasi yaitu tidak tersedianya obat di instalasi farmasi rumah sakit atau stok obat kosong sehingga hal tersebut berkaitan dengan penyiapan obat pada pasien menjadi tidak sesuai dengan permintaan pada resep contohnya oralit yang stok kosong, abocath diganti venflon, dispo 3 diganti dispo 5. Kekurangan ketersediaan obat tersebut bisa mengganggu proses dispensing karena harus mencari terlebih dahulu ke apotek lain sehingga pelayanan menjadi kurang lancar dan juga dapat merugikan pasien yang kemungkinan terlambat mendapatkan obat atau harus mencari di luar rumah sakit (Susanti, 2013).

\section{KESIMPULAN}

1. Faktor penyebab Medication Error fase prescribing meliputi beban kerja yaitu rasio antara beban kerja dan SDM tidak seimbang, gangguan/ interupsi bekerja yaitu terganggu dengan dering telepon, komunikasi yaitu penulisan nama obat tidak lengkap, kondisi lingkungan yaitu suhu area kerja yang kurang mendukung saat bekerja, dan edukasi yaitu penulisan resep yang tidak memenuhi syarat kelengkapan resep.
2. Faktor penyebab Medication Error fase dispensing meliputi beban kerja yaitu tenaga kesehatan tidak mampu menyelesaikan sendiri setiap pekerjaan, gangguan/ interupsi bekerja yaitu terganggu dengan dering telepon, kondisi lingkungan yaitu suhu area kerja yang kurang mendukung saat bekerja, edukasi yaitu penyiapan obat yang tidak sesuai permintaan resep dan komunikasi yaitu sistem komunikasi mengenai stok perbekalan farmasi di instalasi farmasi tidak berjalan lancar.

\section{SARAN}

1. Perlu diperhatikan kembali sistem pelayanan terutama dalam pelayanan pengobatan dan perlu dilakukan penembahan SDM khususnya di Instalasi Farmasi agar rasio antara beban kerja dan SDM seimbang.

2. Perlunya dilakukan penelitian lebih lanjut untuk mengkaji lebih dalam tentang faktor penyebab Medication Error serta mencari hubungan faktor tersebut terhadap kejadian Medication Error.

\section{DAFTAR PUSTAKA}

Aronson, J. K. 2009. Medication Errors: Definition and Classification. British Journal of Clinical Pharmacology. 67: 599-604.

Bayang, A.T., Syahrir, P., Sangkala. 2013. Faktor Penyebab Medication Error di RSUD Anwar Makkatutu Kabupaten Bantaeng [tesis]. Fakultas Kesehatan Masyarakat Universitas Hassanuddin, Makassar.

Donsu, CH.Y. 2016. Faktor Penyebab Medication Error Pada Pelayanan Kefarmasian Rawat Inap Bangsal 
Anak Rsup Prof. Dr. R.D. Kandou Manado. Jurnal Ilmiah Farmasi. 5(3): 2302-2493.

Fitriyaningsih, Nur. 2008. Hubungan Antara Lingkungan Kerja dengan Produktivitas Kerja Karyawan [Skripsi]. Fakultas Psikologi Universitas Muhammadiyah, Surakarta.

Keputusan Menteri Kesehatan RI Nomor 1027/MENKES/SK/IX/2004.

Tentang Standar Pelayanan

Kefarmasian Di Apotek. Menteri Kesehatan RI, Jakarta.

Notoatmodjo, S. 2003. Pendidikan dan Perilaku Kesehatan. Rineka Cipta, Jakarta.

Novianto, P. 2017. Pengaruh Stres Kerja Dan Lingkungan Kerja Kantor Terhadap Kinerja Pegawai Di Badan Perpustakaan Kabupaten Sidoarjo. Jurnal Administrasi Perkantoran. 5(1).

Ojerinde, RN., Adejumo, P. 2014. Factors Associated With Medication Errors Among Health Workers In University College Hospital, Nigeria. Journal of Nursing and Health Science. 3(3): 22-33

Pantawala, AE., Warholak, TL., Sanders, AB., Estad, BL. 2010. A prospective observational study of medication errors in a tertiary care emergency department. 55(6): 522-6.

Permenkes RI Nomor 56. 2014. Tentang Klasfikasi dan Perizinan Rumah Sakit. Menteri Kesehatan RI, Jakarta.
Robbins, S.P., Judge., 2002. Perilaku Organisasi: Organizational Behavior. Jakarta: Salemba Empat.

Siregar, Charles J.P. 2006. Farmasi Klinik Teori dan Penerapan. Penerbit Buku Kedoteran EGC, Jakarta.

Susanti, Ika. 2013. Identifikasi Medication Error Pada Fase Prescribing, Transcribing, dan Dispensing di Depo Farmasi Rawat Inap Penyakit Dalam Gedung Teratai, Instalasi Farmasi RSUP Fatmawati [skripsi]. Fakultas Kedokteran dan Ilmu Kesehatan Prodi Farmasi, Jakarta.

Syamsuni. 2006. Ilmu Resep. EGC, Jakarta. 